\title{
SHOULD ALL PATIENTS WITH ADRENAL INSUFFICIENCY OR A SUBGROUP OF PATIENTS WITH PREDIABETES BE TREATED WITH DUAL-RELEASE HYDROCORTISONE?
}

\section{This is a pre print version of the following article:}

Original Citation:

Availability:

This version is available http://hdl.handle.net/2318/1670462

since 2019-04-25T23:21:12Z

Terms of use:

Open Access

Anyone can freely access the full text of works made available as "Open Access". Works made available under a Creative Commons license can be used according to the terms and conditions of said license. Use of all other works requires consent of the right holder (author or publisher) if not exempted from copyright protection by the applicable law. 


\section{Should all patients with adrenal insufficiency or a subgroup of patients with pre-diabetes be treated with dual-release hydrocortisone?}

Guarnotta et al. compare the effects of dual-release (DR) hydrocortisone 36 months' treatment in 13 patients with primary adrenal insufficiency and 36 with secondary adrenal insufficiency, compared to conventional glucocorticoid treatment. A retrospective evaluation was conducted on the effects of 36 months of DR hydrocortisone therapy on visceral adiposity, insulin secretion and insulin sensitivity. Forty-nine patients with adrenal insufficiency were recruited. They had been on stable conventional glucocorticoid treatment before entering the study and underwent clinical and metabolic evaluation at baseline (during conventional glucocorticoid treatment) and at 12, 24 and 36 months after switching to DR hydrocortisone,

DR hydrocortisone is a formulation that consists of an extended-release core surrounded by an immediate release coating. DR hydrocortisone absorption is rapid (17-20 min for the $20 \mathrm{mg}$ tablet in the fasting state) and can induce an adequate increase in morning cortisol levels with a peak concentration time similar to the one observed with conventional hydrocortisone. However, it produces a more gradual decline in cortisol concentrations than conventional hydrocortisone. DR hydrocortisone was developed to obtain a more physiological circadian cortisol exposure time after a once daily administration (1).

Although a lot of work has been done to optimize glucocorticoid treatment with more physiological formulations of hydrocortisone in the last two decades, there has been no consistent evidence that more physiological replacement of corticosteroid therapy is superior to the conventional once, twice or thrice daily dosages of short-acting corticosteroids. However, previous studies did not carefully measure insulin sensitivity and secretion during DR-hydrocortisone.

Guarnotta et al. report that long-term DR-hydrocortisone is associated with an improvement in insulin secretion and sensitivity in patients with impaired fasting glucose and/or impaired glucose tolerance. The investigators also report an improvement of other parameters (body mass index, waist circumference, glycated haemoglobin and high-density-lipoprotein-cholesterol) in the entire cohort (including those patients without pre-diabetes).

As reported by the Authors, the retrospective design is the main limitation to the study since a cross-over study design would have been preferable for the assessment and verification of the effects of DR hydrocortisone. The small sample size is another principal limitation.

The cohort of patients studied by Guarnotta et al. is too heterogeneous to draw a definitive conclusion on the role of DR-hydrocortisone therapy on glucose homeostasis and insulin sensitivity, but these findings justify for future study on the topic. Future studies should contain adequate numbers of patients with primary and secondary hypoadrenalism.

It is well known that exogenous glucocorticoids affect glucose metabolism, and induce peripheral insulin resistance by impairing insulin signaling. This will lead to decreased glucose disposal and increased glucose production. Moreover, since $\beta$-pancreatic cells undergo several adaptations hyperinsulinaemia may occur (2).

As regards the effects of long-term glucocorticoid replacement therapy on glucose metabolism in patients with hypoadrenalism data are sparse and at times contradictory $(3,4)$.

Previous studies on patients with primary hypoadrenalism reported that high doses of conventional glucocorticoids (e.g. hydrocortisone $30 \mathrm{mg}$ daily or cortisone acetate $37.5 \mathrm{mg}$ daily) showed increased glucose levels and (Homeostasis Model Assessment) HOMA index, compared to controls (5). Furthermore, a study conducted on patients with primary adrenal insufficiency and type 1 diabetes mellitus, showed higher insulin requirements (about 35\%) were needed compared to patients with type 1 diabetes mellitus (6).

Due to the insufficient number and contradictory data of studies on patients with secondary hypoadrenalism during conventional glucocorticoid replacement therapy, no definitive conclusion can be made as to the role of glucocorticoids on glucose metabolism (4). One study (7) reported a reduced prevalence in impaired glucose tolerance and diabetes during hydrocortisone replacement 
with $20 \mathrm{mg} /$ daily, while others found no difference in fasting glucose, insulin levels or glycated haemoglobin after a hydrocortisone reduction from 30 to $15 \mathrm{mg}$ daily (8-10).

Unlike Guarnotta et al, insulin sensitivity and secretion have not been carefully measured in these studies

Most of the previous published studies of DR-hydrocortisone focused on primary adrenal insufficiency, and the data for the effects of DR-hydrocortisone on secondary adrenal insufficiency are scanty. At least four clinical studies have assessed the effect of DR-hydrocortisone on metabolic parameters in patients with primary adrenal insufficiency. In aggregate, these studies demonstrate that DR-hydrocortisone significantly reduces body weight and improves glucose metabolism compared to conventional hydrocortisone replacement therapy and without significant differential effects between normoglycemic patients and diabetic patients (11-14). Therefore, in this subgroup of patients, the suggestion by Guarnotta et al. to treat with DR-hydrocortisone only pre-diabetes patients might not be entirely shareable, since other studies indicate that all the patients with primary adrenal insufficiency should benefit from DR-hydrocortisone therapy.

There have been three studies concerning the metabolic effects of DR-hydrocortisone therapy in patients with secondary hypoadrenalism. Quinkler et al. (12) studied a heterogeneous group of hypoadrenal patients (including 18 secondary adrenal insufficient patients) and reported that DRhydrocortisone decreased glycated haemoglobin compared with conventional treatment in all patients, without specifying the effects of DR-hydrocortisone on secondary forms. Mongioi et al. (14) reported that a cohort of 9 patients with secondary hypoadrenalism showed no significant change in fasting glucose, serum insulin levels, serum glycated haemoglobin and HOMA index after 12 months of DR hydrocortisone treatment. Frara et al. (15) reported no significant change in serum glycated haemoglobin and lipid parameters in a cohort of 14 patients with secondary hypoadrenalism after 24 months of DR-hydrocortisone therapy.

In secondary hypoadrenalism, other pituitary deficiencies or replacement therapies are to be considered as an additional risk factor for metabolic disorders. In particular, insulin resistance is a frequent corollary of growth hormone $(\mathrm{GH})$ replacement therapy and glucocorticoid tissue exposure can be increased during recombinant human GH replacement therapy owing to the effect of GH on $11 \beta$-hydroxysteroid dehydrogenases type 1 (4). In the study by Guarnotta et al, as in previous studies, GH-deficiency patients underwent somatotropin treatment that might influence insulin secretion and sensitivity.

The study by Guarnotta et al. suggests that DR-hydrocortisone therapy might be superior to conventional glucorticoid replacement therapy for patients with pre-diabetes. Larger, casecontrolled randomized studies of patients with both primary and secondary forms are required to confirm this novel and clinically significant finding. 
1. Johannsson G, Bergthorsdottir R, Nilsson AG, Lennernas H, Hedner T, Skrtic S. Improving glucocorticoid replacement therapy using a novel modified-release hydrocortisone tablet: a pharmacokinetic study. Eur J Endocrinol 2009; 161:119-130

2. Rafacho A, Ortsater H, Nadal A, Quesada I. Glucocorticoid treatment and endocrine pancreas function: implications for glucose homeostasis, insulin resistance and diabetes. Eur J Endocrinol. 2014;223:R49-R62.

3. Bornstein SR, Allolio B, Arlt W, Barthel A, Don-Wauchope A, Hammer GD, Husebye ES, Merke DP, Murad MH, Stratakis CA, Torpy DJ. Diagnosis and Treatment of Primary Adrenal Insufficiency: An Endocrine Society Clinical Practice Guideline. J Clin Endocrinol Metab. 2016;101:364-389.

4. Fleseriu M, Hashim IA, Karavitaki N, Melmed S, Murad MH, Salvatori R, Samuels MH. Hormonal Replacement in Hypopituitarism in Adults: An Endocrine Society Clinical Practice Guideline. J Clin Endocrinol Metab. 2016; 101: 3888-3921.

5. Giordano R, Marzotti S, Balbo M, Romagnoli S, Marinazzo E, Berardelli R, Migliaretti G, Benso A, Falorni A, Ghigo E, Arvat E. Metabolic and cardiovascular profile in patients with Addison's disease under conventional glucocyorticoid replacement. J Endocrinolol Invest 2009; 32: 917-923.

6. Elbelt U, Hahner S, Allolio B. Altered insulin requirement in patients with type 1 diabetes and primary adrenal insufficiency receiving standard glucocorticoid replacement therapy. Eur J Endocrinol. 2009;160:919-924.

7. McConnell EM, Bell PM, Hadden DR, McCance DR, Sheridan B, Atkinson AB. Prevalence of diabetes and impaired glucose tolerance in adult hypopituitarism on low dose oral hydrocortisone replacement therapy. Clin Endocrinol (Oxf). 2001;54:593-599.

8.Segerlantz M, Bramnert M, Thomasson R, Manhem P, Laurila E, Groop LC. Effects of morning cortisol replacement on glucose and lipid metabolism in GH-treated subjects. Eur J Endocrinol. 2004;151:701-707.

9. Filipsson H, Monson JP, Koltowska-Häggström M, Mattsson A, Johannsson G. The impact of glucocorticoid replacement regimens on metabolic outcome and comorbidity in hypopituitary patients. J Clin Endocrinol Metab. 2006;91:3954-3961.

10. Suliman AM, Freaney R, Smith TP, McBrinn Y, Murray B, McKenna TJ. The impact of different glucocorticoid replacement schedules on bone turnover and insulin sensitivity in patients with adrenal insufficiency. Clin Endocrinol (Oxf). 2003;59:380-387.

11. Johannsson G, Nilsson AG, Bergthorsdottir R, Burman P, Dahlqvist P, Ekman B, Engström BE, Olsson T, Ragnarsson O, Ryberg M, Wahlberg J, Biller BM, Monson JP, Stewart PM, Lennernäs H, Skrtic S. Improved cortisol exposure time profile and outcome in patients with adrenal insufficiency: a prospective randomized trial of a novel hydrocortisone dual release formulation. $\mathbf{J}$ Clin Endocrinol Metab. 2012; 97: 473-481.

12. Quinkler M, Miodini Nilsen R, Zopf K, Ventz M, Oksnes M. Modified-release hydrocortisone decreases BMI and HbA1c in patients with primary and secondary adrenal insufficiency. Eur $\mathbf{J}$ Endocrinol. 2015; 172: 619-626.

13. Giordano R, Guaraldi F, Marinazzo E, Fumarola F, Rampino A, Berardelli R, Karamouzis I, Lucchiari M, Manetta T, Mengozzi G, Arvat E, Ghigo E. Improvement of anthropometric and metabolic parameters, and quality of life following treatment with dual-release hydrocortisone in patients with Addison's disease. Endocrine 2016; 51: 360-368.

14. Mongioì LM, Condorelli RA, La Vignera S, Calogero AE. Dual-release hydrocortisone treatment: glycometabolic profile and health-related quality of life. Endocr Connect. 2018;7:211219.

15. Frara S, Chiloiro S, Porcelli T, Giampietro A, Mazziotti G, De Marinis L, Giustina A. Bone safety of dual-release hydrocortisone in patients with hypopituitarism. Endocrine 2018 Jan 8. doi: 10.1007/s12020-017-1512-1. 